\author{
Marcin LACH ${ }^{1}$ \\ Opiekun naukowy: Daniel JANCARCZYK ${ }^{2}$ \\ DOI: https://doi.org/10.53052/9788366249837.33
}

\title{
PROJEKT I REALIZACJA SYSTEMU WIZYJNEGo Z WYKORZYSTANIEM KAMERY I STEROWNIKA PLC
}

\begin{abstract}
Streszczenie: $\mathrm{W}$ artykule przedstawione zostały zagadnienia związane $\mathrm{z}$ projektowaniem systemów wizyjnych z zastosowaniem kamer oraz sterowników PLC. W kolejnej części podsumowane zostały dokonania związane $\mathrm{z}$ opracowaniem stanowiska wizyjnego składającego się z kamery Cognex IS 7200 oraz sterownika PLC Siemens S7-1200.W pracy przedstawiono także sposób sterowania stanowiskiem z poziomu panelu HMI oraz przykład wizualizacji wyników.
\end{abstract}

Słowa kluczowe: Projekt, Zastosowanie, Systemy wizyjne maszyn, Sterowniki PLC

\section{DESIGN AND IMPLEMENTATION OF A VISION SYSTEM USING A CAMERA AND PLC CONTROLLER}

\begin{abstract}
Summary: The paper presents issues related to the design of vision systems with consist of cameras and PLC controllers. The next part summarizes the accomplishments related to the development of a vision station consisting of a Cognex IS 7200 camera and a Siemens S7-1200 PLC controller. The article also presents the method of station control from the HMI panel and an example of visualization of results.
\end{abstract}

Keywords: Design, Application, Machine Vision Systems, PLC Controllers

\section{Wprowadzenie}

Automatyzacja procesów produkcyjnych polega na wdrożeniu odpowiednich rozwiązań na danym obszarze produkcyjnym, z wykorzystaniem potencjału maszyn biorących udział w procesie [1]. Modernizacja pod względem automatyzacji niesie za sobą szereg korzyści. Przede wszystkim można wykonywać dany proces z powtarzalnością nie osiągalną dla człowieka. Dobrym przykładem jest także

\footnotetext{
${ }^{1}$ Akademia Techniczno-Humanistyczna w Bielsku-Białej, Wydział Budowy Maszyn i Informatyki, e-mail: mlach@gmail.com

${ }^{2}$ dr inż., Akademia Techniczno-Humanistyczna w Bielsku-Białej, Wydział Budowy Maszyn i Informatyki, e-mail: djancarczyk@ath.bielsko.pl
} 
możliwość automatyzacji prostych, powtarzalnych czynności. Automatyzacja umożliwia także pracę w warunkach trudnych lub szkodliwych dla człowieka. Dzięki niej możemy także zwiększać jakość produktu poprzez wzrost precyzji wykonywanych działań. Nowoczesne rozwiązania automatyzacji procesu pozwalają także na dokładne monitorowanie procesów produkcyjnych oraz katalogowanie i archiwizacje wyników. Systemy wizyjne zyskują coraz większe znaczenie w dziedzinie automatyzacji procesu. Są stosowane powszechnie w maszynach oraz instalacjach automatycznych [2]. Kamery przemysłowe dają nam szeroki wachlarz możliwości. Dzięki nim możemy kontrolować wiele czynników i obiektów, z odpowiednią powtarzalnością. Systemy wizyjne stosowane są także powszechnie tam, gdzie ludzki zmysł wzroku jest zawodny. Możemy sprawdzać między innymi: wymiar, kształt, kolor, połysk, chropowatość, nadruk a także realizować funkcje logiczne i matematyczne w procesorze samej kamery. System wizyjny połączony ze sterownikiem PLC umożliwia pełną kontrole nad procesem wizyjnym, automatyzując go. Możliwe jest odczytywanie rejestrów kamery oraz nadpisywanie ich przez urządzenie sterujące [3].

Systemy wizyjne znajdują szerokie zastosowanie w automatyzacji przemysłu. Najczęściej są one wykorzystywane do wykrywania obecności danego obiektu, bądź jego poprawnej pozycji. Do takich zastosowań wykorzystujemy najprostsze i najtańsze czujniki wizyjne. Bardziej zaawansowane systemy wizyjne umożliwiają między innymi [4]:

- wykrywanie odległości pomiędzy obiektami,

- wykrywanie znaków, liczb i liter,

- detekcje odchyleń i odkształceń,

- odczyt oraz przetwarzanie znaków 2D takich jak QR Code,

- wyszukiwanie kształtów, wraz z dokładnymi danymi o nich,

- obróbkę wyników w postać funkcji matematycznych.

\subsection{Systemy wizyjne}

Czujnik wizyjny to system wizyjny złożony z kamery i procesora obliczeniowego w jednej obudowie. Charakteryzuje się niską rozdzielczością kamery i ograniczonymi możliwościami. Czujniki te stosuje się do realizacji prostych zadań jak na przykład czytanie kodów obiektów lub detekcji obecności detalu. Są one najtańszym typem systemu wizyjnego. Opracowanie inspekcji odbywa się na kilku wbudowanych narzędziach. Do różnego rodzaju zastosowań stosuje się odpowiednie rodzaje czujników wizyjnych [3]. Przykład czujnika wizyjnego prezentuje Rys. 1.

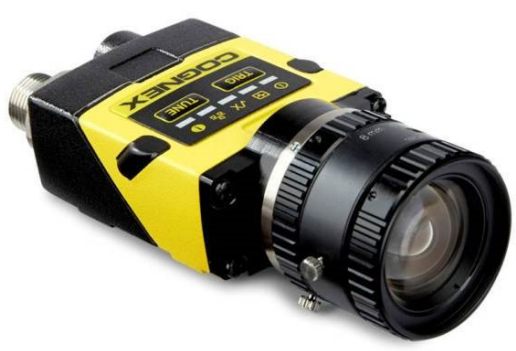

Rysunek 1. Czujnik wizyjny IS 2000 firmy Cognex [3] 
Inteligentna kamera jest to system wizyjny złożony $\mathrm{z}$ kamery $\mathrm{i}$ komputera, zamkniętych $w$ jednej obudowie. Zakres rozdzielczości takich systemów jest duży, do 1600 x 1200 pikseli. Posiadają możliwość komunikacji w wielu standardach. Posiadają własny system operacyjny zaimplementowany w kamerze, oraz możliwość wymiany optyki w zależności od warunków użytkowania. Zakres funkcjonalności takich systemów jest nieograniczony [5]. Przykład inteligentnej kamery pokazano na Rys. 2.

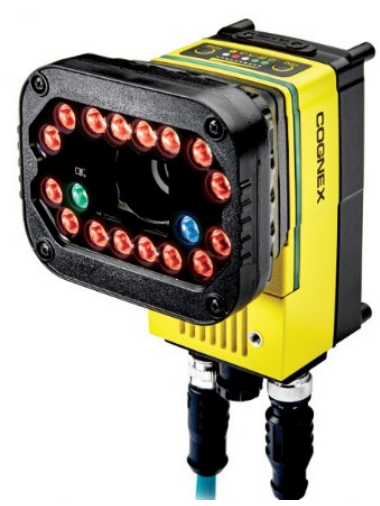

\section{Rysunek 2. Inteligentna kamera D900 firmy Cognex [5]}

Kamera $\mathrm{z}$ komputerem jest to system wizyjny złożony $\mathrm{z}$ kamery i osobnego komputera realizującego system wizyjny. Dzięki zastosowaniu połączenia komputer - kamera, mamy możliwość opracowywania wymagających programów inspekcyjnych. System ten daje nam największe możliwości. Istotny jest dobór kamery i optymalizacja danego stanowiska, pod dany typ inspekcji. Największa zaletą takich systemów jest szeroka funkcjonalność kamery oraz możliwość zastosowania rozwiązań z zakresu techniki komputerowej [6]. Przykład kamery wykorzystywanej do połączenia z komputerem prezentuje Rys. 3.

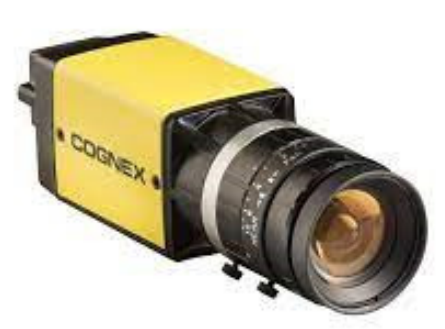

Rysunek 3. Kamera serii 8000 firmy Cognex z możliwościa połaczenia z komputerem [6]

Zaawansowane systemy wizyjne charakteryzują się możliwością doboru i wymiany optyki. Obiektyw kamery składa się z soczewki lub zespołu soczewek odpowiednio ustawionych względem siebie. Ma to na celu uzyskanie odpowiedniego powiększenia oraz kompensacji błędów optyki. System optyczny kamery ma możliwość regulacji ogniskowej automatycznie lub manualnie. Dodatkowo regulujemy także przesłonę 
mechaniczną umieszczoną za soczewką, dzięki czemu ustawiamy ręcznie ilość światła odbieranego przez kamerę. Każdy pierścień regulacyjny na soczewce posiada śrubę ustalającą, zastosowanie której uniemożliwia przesunięcie się pierścieni przez wpływ czynników zewnętrznych. Na każdy obiektyw możemy zainstalować także filtr obrazu w formie nakładki o określonym kolorze. Umożliwia to wykrycie szczególnie trudnych obiektów np. czarnych krawędzi na czarnej powierzchni [7].

\subsection{Sterownik programowalny i panel opraratorski}

Publikacja [1] „Przewodnik programowania dla S7-1200/S7-1500.Opis systemu - wydanie 3/2019" porusza kwestie dotyczące sterowników PLC i posługiwania się nimi. Programowalny sterownik logiczny, PLC to uniwersalne urządzenie mikroprocesorowe przeznaczone do sterowania pracą maszyny lub urządzenia technologicznego. Sterownik musi zostać dopasowany do określonego obiektu sterowania poprzez wprowadzenie do jego pamięci żądanego algorytmu działania obiektu. Cechą charakterystyczną programowalnych sterowników logicznych, odróżniająca je od innych sterowników komputerowych, jest cykliczny obieg pamięci programu [1]. Głównym założeniem wprowadzenia sterowników PLC do przemysłu było zastąpienie układów przekaźnikowych i logicznych przez jedno urządzenie. Początkowo sterowniki PLC stanowiły system sterowania logicznego, w którym sygnały wyjściowe są funkcjami stanów wejściowych, biorąc pod uwagę reguły algebry Boole'a. Dzisiejsze sterowniki PLC realizują bardziej skomplikowane funkcje. Głównymi założeniami programowalnego sterownika logicznego jest:

- zapewnienie niezawodnej pracy w przemyśle od strony oprogramowania i sprzętu,

- spełnianie norm bezpieczeństwa przemysłowego,

- odporność na zaburzenia energetyczne i środowiskowe.

HMI (Human - Machine - Interface) jest to przemysłowy interfejs pośredniczący w komunikacji pomiędzy maszyną/procesem a operatorem [8]. HMI umożliwia wpływ człowieka na proces produkcyjny oraz nadzór poprzez wyświetlanie stanu maszyny. Panel posiada własny system operacyjny, a jego programowanie odbywa się w dedykowanym dla każdego producenta środowisku. Obsługę HMI realizuje się najczęściej poprzez ekran dotykowy, chociaż niektóre panele są wyposażone w dodatkowe przyciski funkcyjne. Oprócz wyżej wymienionych, panel operatorski zapewnia możliwość raportowania, archiwizowania i analizowania danych pochodzących $\mathrm{z}$ procesu/maszyny. Ważną rzeczą w programowaniu paneli operatorskich jest GUI (Graphical - User - Interface). Poprawnie zaprojektowany interfejs użytkownika pozwala ułatwić obsługę panelu oraz zwiększa jego przejrzystość. Przykład panelu HMI prezentuje Rys. 4.

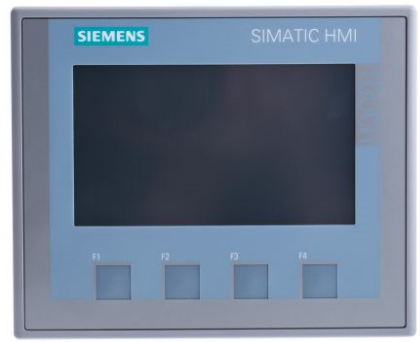

Rysunek 4. Panel HMI KT400 marki Siemens [8] 


\section{Projekt i realizacja systemu wizyjnego}

Poniższy rozdział poświęcony jest opisowi zaprojektowanego i zbudowanego stanowiska, wraz z omówieniem programu w środowisku TIA PORTAL V13, wizualizacji panelu HMI oraz przedstawieniem inspekcji stworzonej na potrzeby wykrywania detali.

Stanowisko zaprezentowane na Rys. 5. składa się z kamery firmy Cognex typu IS 7200 skomunikowaną przez sieć profinet ze sterownikiem PLC Siemens S7-1200 oraz panelem HMI Siemens KTP 600. Całość zasilana jest przez regulowany zasilacz prądu stałego $24 \mathrm{VDC} / 2.5$ A o mocy maksymalnej 60W. Kamera skierowana jest na pole odkładcze monety, po wykryciu obecności monety za pomocą czujnika indukcyjnego który jest umieszczony na polu odkładczym, kamera wykonuje zdjęcie. Dzięki zastosowaniu oświetlacza, uzyskujemy powtarzalną ilość światła trafiającego do ogniska. Zabieg ten niweluje wpływ światło - cienia na wynik inspekcji.

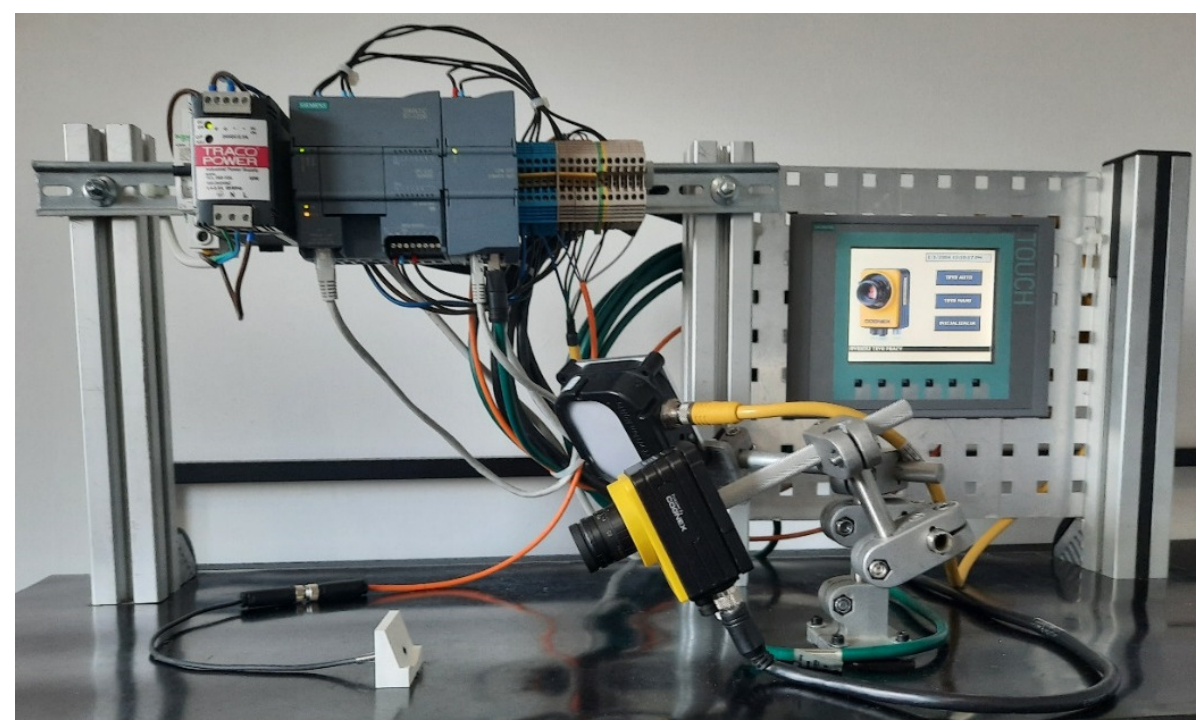

Rysunek 5. Stanowisko detekcji rodzaju monety [opracowanie własne]

Nadzór nad procesem i wymianą danych sprawuje sterownik PLC. Sterownik wykonuje porównanie wyników inspekcji, z informacjami zapisanymi w bloku danych i decyduje o rodzaju monety znajdującej się na polu odkładczym. Dzięki zastosowaniu panelu HMI możliwe jest sterowanie procesem detekcji oraz odczytywanie wyników inspekcji. Możliwości modyfikacji i modernizacji stanowiska są praktycznie nie ograniczone. Wraz z powiększeniem liczby monet w bazie danych, możemy dodawać do inspekcji kolejne narzędzia, które pozwolą na dokładniejsze działanie procesu wykrywania. To samo dotyczy programu PLC i wizualizacji, które mogą zostać rozbudowane o dodatkowe funkcję.

Wykaz komponentów użytych do budowy stanowiska:

- sterownik PLC Siemens S7-1200 6ES7 212 - 1AE40 - 0XB0,

- panel HMI Siemens KTP600 Basic color PN 6AV6 647 - 0AD11 - 3AX0,

- kamera Cognex IS - 7200, 
- oświetlacz Smart Vision Lights typu ODS75-WHI,

- switch sieci Ethernet/profinet Siemens CSM 1277,

- zasilacz 24 VDC Traco power TCL 060-124.

Detekcja monety odbywa się poprzez czujnik indukcyjny umieszczony na polu odkładczym. Po umieszczeniu monety na miejscu w trybie automatycznym sygnał z czujnika uruchamia blok czasowy sterownika, który zezwala na zdjęcie z kamery po pewnym ustalonym czasie. Kamera po zrobieniu zdjęcia wyszukuje odpowiednie krawędzie podczas przejścia kolorów z ciemnego na jasny Rys. 6. System wizyjny bierze pod uwagę wszystkie kształty które są okręgiem. Kamera oblicza ilość pikseli na obwodzie wyszukanego okręgu. Ilość pikseli jest wysyłana do sterownika PLC, który wykonuje porównanie z zapisanymi wartościami w data bloku. Jeśli ilość pikseli jest zgodna $\mathrm{z}$ wartościami zapisanymi w sterowniku, otrzymujemy odpowiedni komunikat na panelu HMI zawierający informację o odczytani oraz zdjęcie odpowiedniej monety.

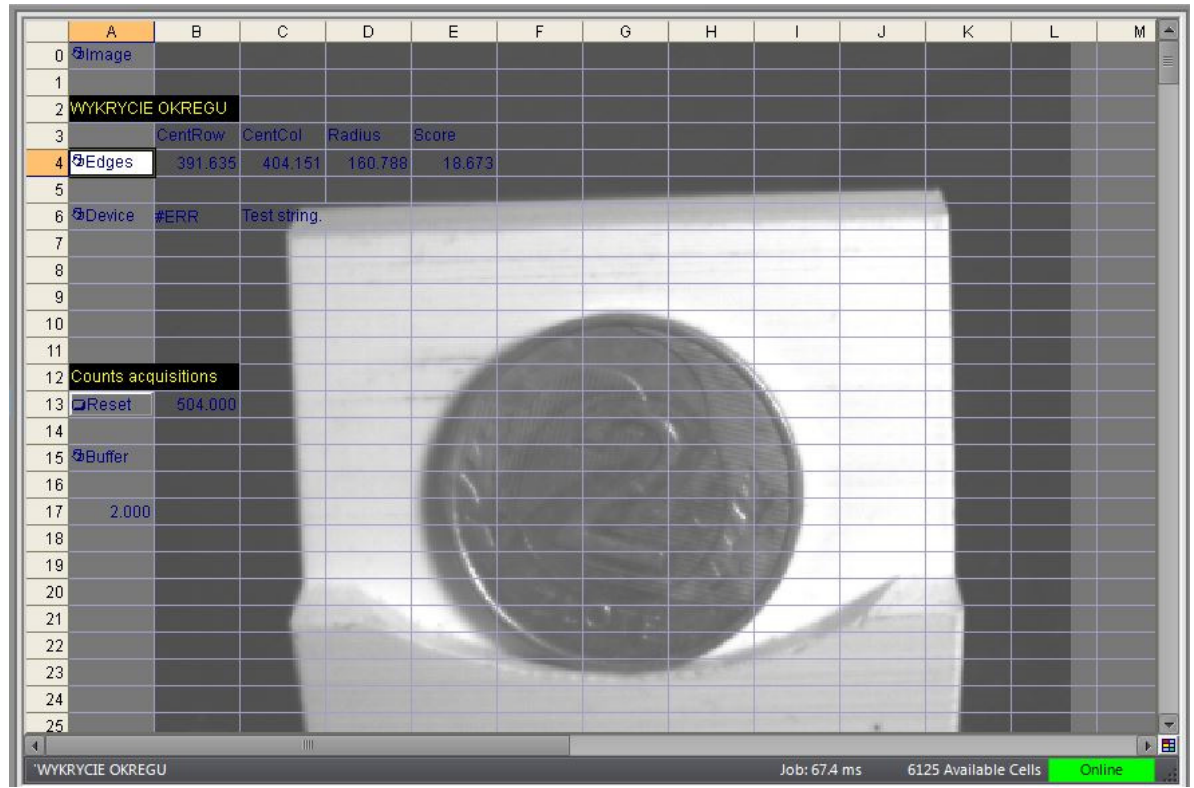

Rysunek 6. Program inspekcyjny przy wykrywaniu nominatu 2 zt [opracowanie własne]

Od momentu włączenia, na panelu HMI otrzymuje się odpowiednie komunikaty, które ułatwiają nam poruszanie się po wizualizacji Rys. 7. W pierwszym kroku należy wybrać tryb pracy kamery, a następnie otrzymuje się instrukcje ułatwiające użycie stanowiska. 


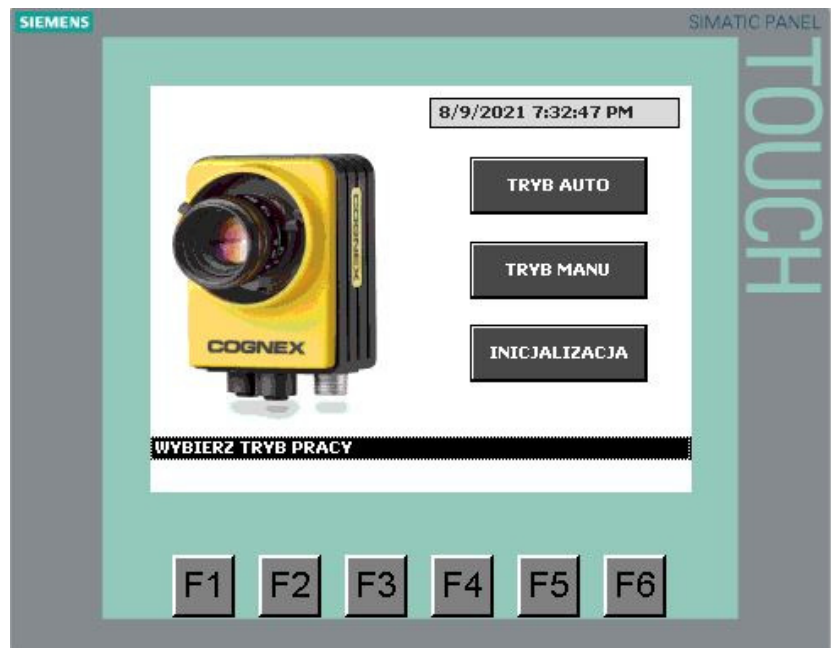

Rysunek 7. Strona główna aplikacji z przykładowym komunikatem [opracowanie wtasne]

Z panelu HMI można także odczytać podstawowe informacje diagnostyczne, takie jak status kamery, status inspekcji, zezwolenie na wykonanie zdjęcia, oraz obecność danych z kamery w bazie danych Rys. 8. W przypadku nie wykrycia kształtu przez kamerę, lub braku odczytanej wartości pikseli w data bloku, na panelu wyświetla się odpowiedni komunikat wraz z grafiką.
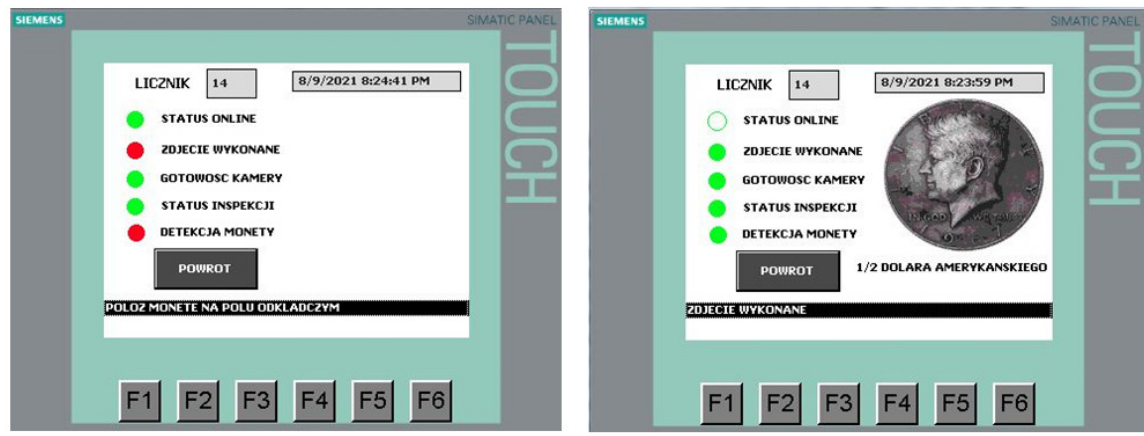

\section{Rysunek 8. Okno trybu automatycznego prezentujace aktualny status inspekcji [opracowanie własne]}

Działanie stanowiska można także monitorować za pomocą diod umieszczonych na obudowie sterownika, kamery oraz switcha komunikacyjnego. W trybie manualnym obsługa stanowiska wygląda podobnie z tym że można wybrać częstotliwość wyzwalania trigera Rys. 9. Jest to pomocne podczas ustawiania pozycji kamery względem pola odkładczego lub kontroli powtarzalności inspekcji. W trybie manualnym istnieje także podgląd podstawowych parametrów stanowiska w postaci diod na panelu HMI. Tryb inicjalizacji resetuje połączenie z kamerą, dzięki czemu możemy zresetować statusy otrzymywane na wejścia sterownika. 


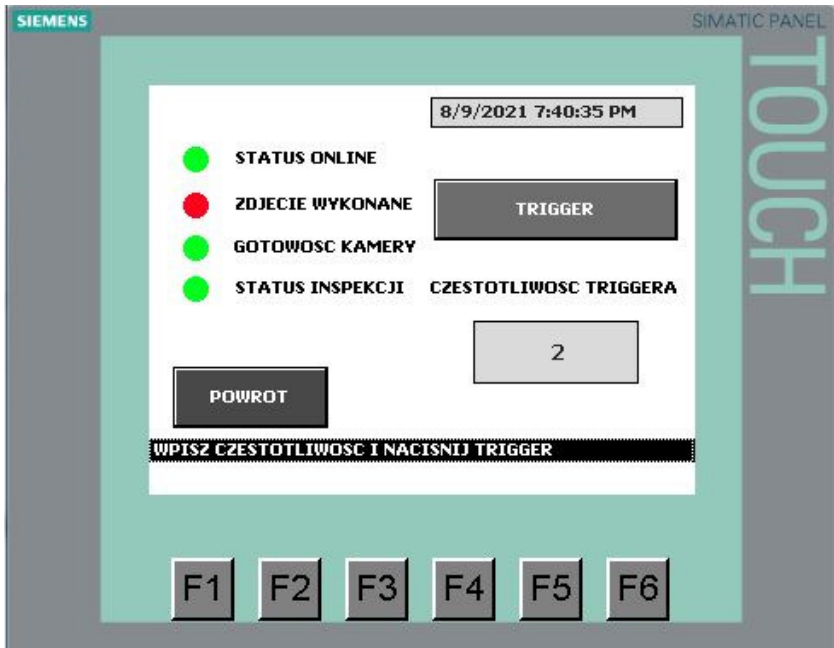

Rysunek 9. Okno trybu manualnego [opracowanie własne]

Konfiguracja sprzętowa oraz programowa została napisana w oprogramowaniu Tia Portal V13 firmy Siemens. Najtrudniejszym elementem konfiguracji było skonfigurowanie interfejsu sieci profinet. Implementacja urządzenia do sieci profinet w Tia Portal opiera się na plikach GSD. Są to pliki konfiguracyjne, dzięki którym możemy w łatwy sposób zaprojektować topologie sieci i skomunikować ze sobą urządzenia. Wybierając plik konfiguracyjny kamery, możemy rozpocząć jej konfigurację sieciową. Należy ustawić odpowiednie IP, takie w jakie wyposażona jest kamera. W kolejnym kroku należy przypisać odpowiednie obszary, na których będzie odbywać się wymiana danych pomiędzy sterownikiem PLC a kamerą. Widok okna konfiguracyjnego przedstawiono na Rys. 10.

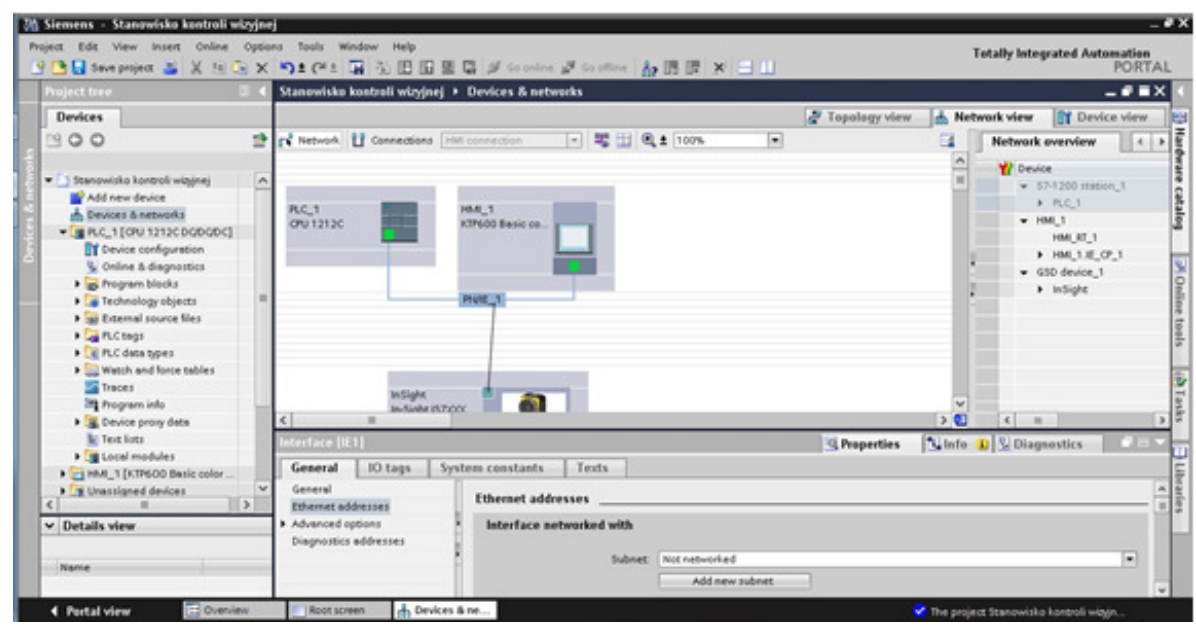

Rysunek 10. Konfiguracja sieci profinet w środowisku Tia Portal [opracowanie wtasne] 
Inspekcja wizyjna dla kamery została wykonana w dedykowanym do tego celu oprogramowaniu In-Sight Explorer. Program ten to wielofunkcyjne narzędzie służące do konfigurowania i programowania systemów wizyjnych firmy Cognex. Umożliwia ono ustawianie wszystkich parametrów kamery według preferencji. In-Sight Explorer wykorzystuje się także do tworzenia i programowania inspekcji. Po podłączeniu się z kamerą, w centralnej części ekranu ukazuje się ostatnio wykonane zdjęcie wywołanego programu. Jest to także okno podglądu i edycji inspekcji. Po lewej stronie wyświetla się topologia sieci kamer i systemów wizyjnych, umożliwiająca swobodne przełączanie się pomiędzy kilkoma urządzeniami. W górnej części programu znajduje się pasek narzędzi, dzięki któremu możemy edytować i konfigurować inspekcję. Można odczytać z niego także funkcję znajdującą się w określonej komórce inspekcji. Prawa strona ekranu obrazuje paletę funkcji snippetów (zadań automatycznych) oraz okno testowe Rys. 11. Program posiada 2 tryby programowania sensorów. Jeśli nie wymaga się inspekcji zaawansowanej lub kamera nie posiada takich opcji, stosujemy opcję Easy Builder. W trybie Easy Builder programowania kamery, mamy dostęp do wstępnie skonfigurowanych. przestrzennie zdefiniowanych i logicznie zintegrowanych funkcji programu In-Sight Explorer. Jeśli zachodzi potrzeba pełnej kontroli nad inspekcją i korzysta się z zaawansowanych narzędzi systemu wizyjnego, wybrać należy trybu arkusza kalkulacyjnego - spreadsheet. W tym trybie mamy dostęp do wielu narzędzi i filtrów, które sami konfigurujemy.

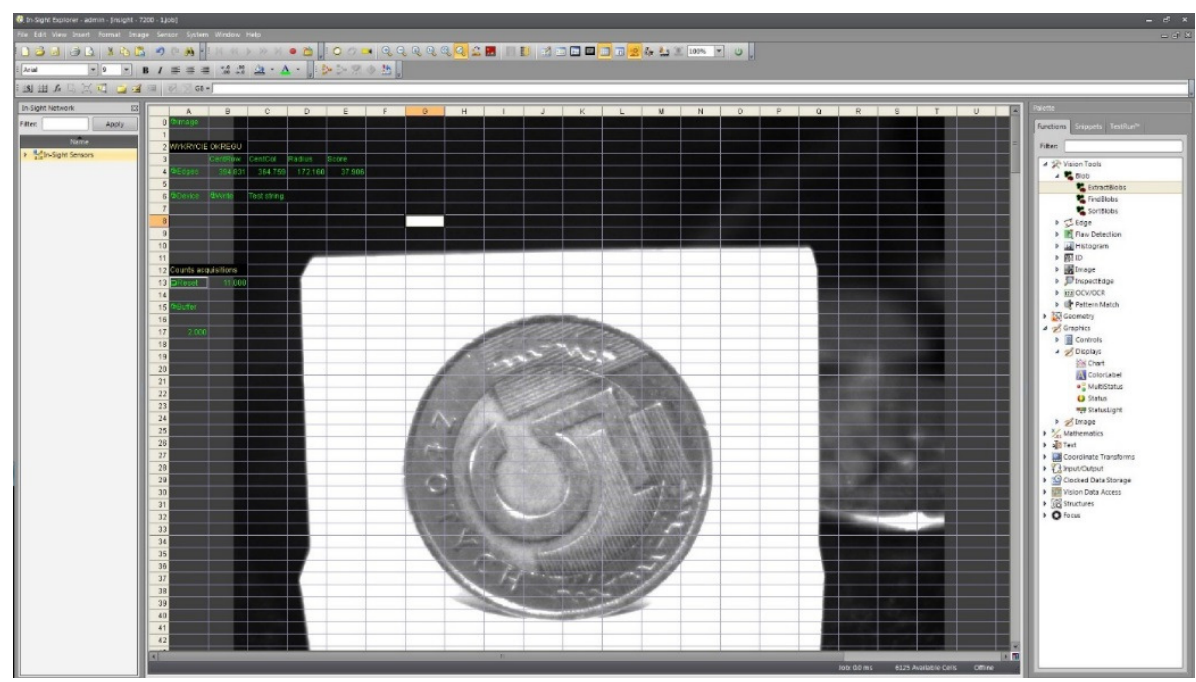

Rysunek 11. Strona główna programu In-Sight Explorer [opracowanie własne]

\section{Podsumowanie i wnioski}

W ramach pracy zostało zaprojektowane, skonstruowane i zaprogramowane stanowisko systemu wizyjnego z wykorzystaniem kamery i sterownika PLC. Do procesu detekcji użyto monety. Wiedza pozyskana z literatury umożliwia zapoznanie się z elementami stanowiska wizyjnego, oraz programami wymaganymi do realizacji 
jego funkcji. Praca przedstawia problem i przykładowe rozwiązanie w konstruowaniu stanowisk opierających swoje działanie o system wizyjny. Rozwiązania zaprezentowane w pracy, można zastosować i implementować w każdym stanowisku, którego podstawę stanowi wizja. W pracy przedstawiono także sposób sterowania stanowiskiem z poziomu panelu HMI oraz przykład wizualizacji wyników. W ramach pracy udało się rozwiązać problem doboru parametrów inspekcji przy zachowaniu powtarzalności podczas zmiany detali. Problem został rozwiązany dzięki regulacji parametrami programu systemu wizyjnego oraz zastosowaniu oświetlacza.

Automatyzacja stanowisk pracy wciąż się rozwija. Procesy wykorzystujące kamery i systemy wizyjne stanowią coraz szersze zastosowanie w przemyśle i usługach. $\mathrm{Z}$ pewnością udział zautomatyzowanych systemów wizyjnych będzie rosnąć. Coraz szybszy rozwój umożliwia stosowanie kamer w praktycznie każdych warunkach. Największą zaletą systemów wizyjnych jest większa dokładność i powtarzalność względem oka ludzkiego. Wykrywanie różnic pomiędzy kształtami detalu to jedno z najczęstszych zastosowań czujników wizyjnych.

\section{LITERATURA}

1. Przewodnik programowania dla S7-1200/S7-1500. Opis systemu wydanie 3/2019, https://publikacje.siemensinfo.com/pdf/52/Przewodnik\%20programowania\%20d la\%20S7-1200\%20S7-1500.pdf [dostęp: 08.2021].

2. GOLNABI H., ASADPOURB A.: Design and application of industrial machine vision systems, Robotics and Computer-Integrated Manufacturing, Volume 23, Issue 6, 2007, pp. 630-637.

3. Cognex Hardware_Connections https://support.cognex.com/en-pl/downloads/insight/training [dostęp: 27.08.2021].

4. LÁSZLÓ Galata D., MÉSZÁROS L., KÁLLAI-SZABÓ N., SZABÓ E., PATAKI H., MAROSI G., NAGY Z.: Applications of machine vision in pharmaceutical technology: A review, European Journal of Pharmaceutical Sciences, Volume 159, 2021.

5. Cognex Inputs_Outputs https://support.cognex.com/en-pl/downloads/insight/training [dostęp: 27.08.2021].

6. Cognex Spreadsheets_ImageAcquisition https://support.cognex.com/enpl/downloads/in-sight/training [dostęp: 08.2021].

7. PATIL M., TOPOROVSKY J.: Integration of vision system, intelligent ROBO actuator, HMI and PLC to design a universal quality inspection or control machine, i-manager's Journal on Mechanical Engineering, vol. 2, no. 3, 2012, pp. 5-14.

8. SIMATIC HMI WinCC (TIA Portal). Edition 05/2021 https://cache.industry.siemens.com/dl/dlmedia/201/109794201/att_1069740/v1/1 44184611595_en-US/en-US/index.html [dostęp: 08.2021]. 